\title{
Mito en materia: Garcilaso de la Vega y el objeto encontrado
}

\author{
Enrique García Santo-Tomás \\ University of Michigan \\ enriqueg@umich.edu
}

Recepción: 13/02/2015, Aceptación: 07/05/2015, Publicación: 22/12/2015

\begin{abstract}
Resumen
El presente ensayo comenta el último libro de la hispanista norteamericana Mary Barnard en torno a la poesía de Garcilaso y su representación de la llamada 'cultura material' en el Siglo de Oro. Para ello reflexiona sobre el estado de la disciplina enmarcando dicho estudio dentro de una tendencia crítica que, en los últimos años, ha ofrecido nuevas formas de analizar el Renacimiento europeo.
\end{abstract}

Palabras clave

Barnard; Garcilaso de la Vega; cultura material; objeto; consumo

\begin{abstract}
Myth into Matter: Garcilaso de la Vega and the Found Object

This essay examines Mary Barnard's recent study on Garcilaso's poetry and the so-called 'material culture' of the Spanish Golden Age. It does so by reflecting on the state of the discipline and by framing this book within a scholarly trend that in the last few years has provided new ways of looking at the European Renaissance.
\end{abstract}

\section{Keywords}

Barnard; Garcilaso de la Vega; material culture; object; consumption 
Las últimas tres décadas han reavivado el estudio de la cultura material en las letras áureas, ya sea desde el objeto en sí o de sus complejas relaciones con el sujeto, ya sea en el rastreo de sus propiedades sensoriales e intelectuales. La producción cultural de los siglos XVI y XVII ha sido estudiada en los últimos años enfocando la función que ejercieron estos bienes de consumo en la vida cotidiana y en las ficciones en torno a ella. El más reciente de estos análisis es el nuevo libro de la hispanista norteamericana Mary Barnard, titulado Garcilaso de la Vega and the Material Culture of Renaissance Europe, cuya lectura me sirve como punto de partida para reflexionar sobre los retos de esta reciente tendencia interpretativa. Busco así enmarcar este análisis en su contexto interpretativo e institucional -firmemente anclado en el sistema universitario estadounidense- $y$ ofrecer nuevas observaciones que nos acerquen a la cultura renacentista y barroca de nuestros clásicos de una forma más rica y compleja.

Este interés desde la filología hispánica no se habría dado de no existir una completa tradición crítica anglosajona, con varios lustros de intensa producción intelectual y numerosos encuentros académicos. Este nuevo escrutinio del Wunderkammer barroco como árbitro cultural y no sólo como mero producto de consumo maduró ya en lo que, desde el ámbito de la crítica inglesa en los años ochenta, se conoció como Nuevo materialismo. Se trataba de una propuesta que avanzaba algunos de los presupuestos teóricos divulgados con éxito por el Nuevo Historicismo en Norteamérica, si bien centrándose además en el recorrido semántico de los objetos para construir identidades individuales y colectivas. La cultura material del período y las implicaciones sociales, económicas y políticas que definían estas nuevas vías de estudio dieron lugar a excelentes análisis interdisciplinarios de los sistemas de comercio, de las zonas de contacto que fueron el resultado de estos intercambios, y del efecto producido por el desarrollo mercantil en la Europa de Shakespeare, Cervantes, Copérnico, Galileo y Descartes. ${ }^{1}$ Se comenzó entonces a prestar mayor atención a los procesos migratorios de los bienes de consumo y a su reinterpretación en nuevos contextos, al papel del lujo en la sociedad cortesana o al efecto de los gremios locales en lo que podría considerarse, en términos modernos, como producción en masa. La expresión literaria supo dar cuenta de estas nuevas preocupaciones en una sociedad cada vez más atraída por la bagatela, por lo ligero y por lo frívolo. Esta tensión emanante de la convivencia de objetos comunes y necesarios con bienes de consumo raros o extraordinarios dio lugar, como es sabido, a frecuentes críticas por parte de los censores, que tachaban a muchos de estos urbanitas de nueva cuña de afeminados, cuando no de lacras sociales que obstaculizaban el buen funcionamiento de la república. Así fue el caso, por ejemplo, de la incipiente industria del sombrero en una sociedad urbana particularmente atenta a los mecanismos de distinción, y que fue objeto de alusiones fascinantes en El cortesano descortés (1621) de Alonso

1. Con respecto a este último, véase García Santo-Tomás (2015). 
Jerónimo de Salas Barbadillo. Por ella circulaban sombreros falsos y auténticos, sombrereros y rufianes con ánimo de lucro y burla, pero lo que atravesaba la pieza de principio a fin era una evidente sátira de determinados usos cortesanos ya en vías de obsolescencia, en los que el objeto marcaba la diferencia. ${ }^{2}$ Esta nueva atención a formas y materiales, a lo vulgar y lo exclusivo, a lo local y lo foráneo o al original y la copia galvanizó también el espíritu coleccionista en la Península: fascinantes resultan los testimonios de ciertos virtuosi como Juan de Espina, Jerónimo de Ayanz y Vincencio Juan de Lastanosa, así como las noticias sobre el afán acumulador de nobles como el Duque de Villahermosa (gran coleccionista de monedas), el Duque de Villamediana (dueño de un impresionante ajuar de joyas) o el Marqués de Leganés y su famosa colección de armas. Sobre algunos de ellos se ha escrito en trabajos recientes, ${ }^{3}$ ofreciendo nuevas lecturas y datos de esta faceta de la cultura barroca. Si el estudio de tal o cual autor en sus relaciones con la vida social del objeto que se idolatra, desea o rechaza siempre resulta estimulante, también lo es el análisis de ideas que viajan más allá de fronteras locales encarnadas en formas y materias. ${ }^{4}$

Uno de los aspectos más atractivos de estas aportaciones recientes ha resultado ser la apertura del saber filológico a otras disciplinas, como la antropología, la arqueología, la historia, la sociología o la etnografía. La "cultura material» (material culture) ha madurado como un área de estudio no disciplinar y abierta a todo tipo de enfoques. Desde su origen, ligado a las teorías de consumo - estudiadas por el crítico Daniel Miller en los años ochenta - y a la arquitectura —analizadas recientemente por el arqueólogo Victor Buchli-, el término parece haberse extendido rápidamente a través de colecciones y revistas de creciente prestigio, como Journal of Material Culture, Cultural Trends, October o Representations, que han abrazado esta "no-disciplinariedad» como una de sus virtudes prácticas y ventajas conceptuales. ${ }^{5}$ En ellas se ha defendido que el tratamiento de los objetos no ha dado lugar a una disciplina autónoma, pues los objetos son ya en sí significativos. Esto ha permitido al estudioso ampliar el campo de análisis a cuestiones de identidad en la relación sujeto-objeto, demostrando así cómo los consumidores pueden - y deben - ser, en este sentido, un campo de exploración tan necesario como el de los productores mismos. Trabajos pioneros

2. Los conceptos de distinción y diferencia, provenientes de la sociología de Pierre Bourdieu, han sido ya explorados en la cronología que nos ocupa en estudios como los de Gutiérrez (2005) y García Santo-Tomás (2008), entre otros.

3. Ver, por ejemplo, la antología editada por Mancall y Bleichmar (2013), que constituye uno de los mejores estudios en torno a este fenómeno; excelente es también el trabajo de Marcaida López (2014).

4. Así lo ha sugerido recientemente el crítico norteamericano Greene (2013) en su estimulante e innovador estudio.

5. Al lector interesado en el asunto remito, como punto de partida, a Miller (2002), así como a los volúmenes editados por Buchli (2002) y Tilley et al. (2013). 
en el ámbito anglosajón como los de Simon Schama (The Embarrassment of Riches. An Interpretation of Dutch Culture in the Golden Age), Lisa Jardine (Worldly Goods. A New History of the Renaissance), Ann Rosalind Jones y Peter Stallybrass (Renaissance Clothing and the Materials of Memory), o antologías como las editadas por Peter Stallybrass, Margreta de Grazia y Maureen Quilligan (Subject and Object in Renaissance Culture) o Lena Cowen Orlin (Material London, ca. 1600), han ofrecido un panorama crítico indispensable en el que brillan también aportaciones ya clásicas de historiadores de la cultura como Raffaella Sarti (Vita di casa. Abitare, mangiare, vestire nell'Europa moderna) y Daniel Roche (Histoire des Choses Banales; naissance de la consommation, XVII -XVIII siècles), entre otros. A estas referencias se han unido en fechas recientes, desde el terreno de la filología española, libros como los de Enrique García Santo-Tomás, Modernidad bajo sospecha: Salas Barbadillo y la cultura material del siglo XVII o Materia crítica: formas de ocio y de consumo en la cultura áurea, donde se abordan asuntos que habían pasado desapercibidos en el estudio de la cultura áurea y donde se ha buscado abrir la puerta a un análisis sobre la cultura de consumo. ${ }^{6}$

Desde esta línea de investigación, quiero formular una serie de preguntas como pórtico a lo que comentaré en las próximas páginas. Me centro en la figura de Garcilaso, quien supo como nadie capturar la fascinación y atractivo de una cultura para él nueva, moderna y hedonista, como fue la napolitana, y de la cual consiguió plasmar en sus sonetos tantos matices y sabores. Fueron muchos de estos sonetos homenajes a lo placentero a través de usos y conductas, y también constituyeron reflejos de la propia sorpresa y fascinación que esta sociedad causaba sobre el poeta. Esto no significó que se abandonaran las fuentes de inspiración, sino todo lo contrario: el propio mito, como nos ha recordado en un excelente análisis Oliver J. Noble-Wood, deviene materia a través de complejas manipulaciones que incluyen «allusion through periphrasis, subtle modifications to individual narrative elements, and unexpected parallels between situations faced by the poem's protagonists and those involving the gods of Antiquity» (62). A partir de aquí, Garcilaso nos anima a preguntarnos: ¿qué papel jugó el objeto de lujo en la poesía renacentista, y cómo se captaron sus múltiples valencias en un formato como el soneto, en esa precios(ist) a well wrought urn, tal y como nos sugirió hace ya más de medio siglo el crítico norteamericano Cleanth Brooks?? ¿Qué tratamiento recibieron determinados materiales y sustancias novedosas en la exploración y el viaje a ciudades míticas y paisajes ignotos? ¿Cómo se capta la novedad de lo exótico, de aquello que resulta insustituible y único del mundo renacentista y de sus redes diplomáticas? ¿En qué momentos el objeto encarna el encanto misterioso de lo femenino, o cómo se asocia a determinados usos varoniles gracias a aspectos tan del momento como la amistad o el secreto? ¿Y cómo,

6. Véase, igualmente, Barnard y De Armas, eds. (2013).

7. Véase Brooks (1956). 
por ejemplo, logró el nuevo espíritu impregnado de sprezzatura cortesana en autores como Castiglione dotar a determinados bienes de una dignidad, de una utilidad o de una fascinación antes no vista? La tradición que recibe el toledano resulta ser, como ya se ha escrito en multitud de ocasiones, seminal a la hora de transmitir este sentimiento de maravilla. El estudio de Mary E. Barnard busca dar respuestas a algunas de estas preguntas, engastándose así en esta genealogía crítica y unéndose con ello a otras contribuciones recientes que, desde el ámbito anglosajón, ofrecen estimulantes lecturas de la primera generación de poetas petrarquistas. Garcilaso, según nos recuerda Barnard, fue a fin de cuentas «a pioneer in another sense, that is, in engaging the material culture of his time and making objects central to his poems as sites of lyric discourse and cultural exchange. He was intimately familiar with Europe's ruins and antiquities, with its newly commissioned sumptuous objects, and with the abundance of religious and practical objects filling up the physical and mental landscape of writers and artists of the early sixteenth century» (171): un escritor siempre consciente de lo voluble y maleable de la memoria, aunque se materializara en inscripciones literarias o pictóricas.

Garcilaso de la Vega disfrutó de importantes estancias en Italia (1529-30, 1532-36), donde visitó ciudades como Roma, Mantua, Bolonia y Ferrara, y vivió en Nápoles, auspiciado por Pedro de Toledo y su sobrino Fernando, tercer Duque de Alba. En esta suerte de exilio biográfico — pero también de festín intelectual, rodeado de Luigi Tansillo, Marcantonio Epicuro, Antonio Sebastiano Minturno o Bernardino Martirano, que tanto le aportaron- concibió no pocas composiciones que hoy se consideran de lo mejor de su producción, entre ellas un buen número de sonetos (XII, XIII, XV, XVI, XIX, XXIII, XXIV, XXVIII, XXIX, XXX, XXXI, XXXII, XXXIII, XXXV...) dejando sentir entre sus versos una rica cultura de ocio placentero. ${ }^{8}$ El poeta toledano, sostiene Barnard, fue muy sensible a la presencia material de algunos bienes de consumo, y en muchas de estas piezas los tapices, retratos, urnas, estatuas, armas e instrumentos musicales desempeñaron un papel significativo, como portadores de una cultura admirada y proyectada en diferentes formas estróficas. Logró acceder así a una tradición que concebía el objeto no solo en su singularidad, sino también desde su capacidad de asombrar y seducir en la exposición, en la ordenación y en la acumulación: "Garcilaso's gathering of lyric objects» — escribe Barnard- «finds its analogue in the Italian studiolo, the private chamber of wealthy aristocrats designed for reading and meditation, and a venue for displaying the taste and culture of its owner through books and artifacts» (9). A través de cuidados análisis y de una ejemplar atención al detalle, la hispanista norteamericana propone una original y esti-

8. Se echa de menos en Barnard la presencia de los estudios de Hernando Sánchez — como por ejemplo los de 1994 y 2001—, que resultan fundamentales a la hora de entender el contexto histórico que se estudia. 
mulante interpretación del espacio compartido por objeto, texto y memoria en donde incluso el cuerpo humano deviene objeto de exploración, en un ámbito propicio para el estudio de estados melancólicos tanto como para el disfrute de placeres mundanos. Estamos, pues, ante uno de los trabajos más atractivos y sugerentes de los últimos años en torno al poeta toledano, en especial en lo relativo a asuntos como la psicología del yo y su relación con la herencia cultural, así como con el juego entre oralidad y escritura. El de Barnard es un análisis que conecta con muchas de las reflexiones contemporáneas en torno a la fascinación por los bienes materiales, firmado por una de las mayores conocedoras de la poesía renacentista, desde un hispanismo como el norteamericano en el que no han faltado excelentes garcilasistas (Elias Rivers, Daniel Heiple, Anne Cruz...) en este último medio siglo. Propone, además, una lectura más atenta a la artificialidad y convención de ciertos estados de ánimo, partiendo de la premisa avanzada por Heiple en su momento y renovada ahora por Noble-Wood, de que «sincerity is always a construct» (62). Por ello, el libro que se comparte en la lectura cómplice, el lienzo que se regala o el tapiz que conmemora son «good for performing emotions» (8), como también lo son para trazar nuevas conexiones, para construir nuevas amistades o para pagar favores. De lo que la autora llama "Garcilaso's discursive studiolo» (9) se encargan entonces los seis capítulos que componen la espina dorsal del libro, cada uno de ellos constituido por «a set of objects cast in unique roles» (11).

El capítulo primero, "Weaving, Writing and the Art of Gift-Giving», hace un repaso de algunos de los tapices más significativos del momento, y sostiene que Garcilaso debió de estar familiarizado con algunos de ellos así como con sus funciones. El uso del oro, por ejemplo, dotaba a estas piezas de una sofisticación y relumbre inigualables, y así lo hace ver, sostiene Barnard, en su poesía:

Las telas eran hechas y tejidas del oro que'l felice Tajo envía... y de las verdes ovas, reducidas en estambre sotil, cual convenía, para seguir el delicado estilo del oro, ya tirado en rico hilo. (20)

Barnard toma como punto de partida esta Égloga III, en la que los tapices de las ninfas sirven de símbolo del propio tejido del poema, constituyéndose en "the point at which cultures meet, a warp of Greco-Roman mythology and Italian subtexts intersecting with a weft of Castilian words» (26). Si, como observó Roland Barthes, todo texto es un tejido de diversos componentes, la autora sugiere que el poeta que 'teje' esta mezcla de tradiciones culturales con su pluma se encarna en la página en la 'escritura' particular de sus ninfas. El recurso poético del tapiz también se convierte en Garcilaso en pantalla (screen) que filtra el lamento del poeta, en un espacio en donde sus figuras asumen «bits of discourse, which stand for a disguised lyric self-reflection» (35). 
Se da paso así al capítulo segundo, «Empire, Memory, and History», en el cual Barnard se detiene en el recuento visual más impactante de la Campańa de Túnez: el conjunto de doce tapices bordados por Willem de Pannemaker entre 1549 y 1554 a partir de los dibujos del artista flamenco Jan Cornelisz Vermeyen durante dicha campaña. La hispanista norteamericana conecta estas famosas composiciones con el soneto XXXIII, «A Boscán desde La Goleta» y con la Oda latina dedicada a Juan Ginés de Sepúlveda. Aunque todos los dibujos (salvo uno) de la campaña tunecina pintados por Vermeyen se han perdido, han sobrevivido doce bocetos a gran escala que se encuentran en el Kunsthistorisches Museum en Viena, así como diez de los doce tapices originales que acoge el Palacio Real de Madrid. Siguiendo los conceptos de distancia, espacio y memoria desarrollados por la historiadora del arte Mary Carruthers en sus libros clásicos The Book of Memory (1991) y The Craft of Thought (1998), Barnard lleva a cabo estimulantes conexiones entre diferentes 'tejidos', el del hilo y el de la pluma, sugiriendo que el encuentro de Garcilaso con Túnez/Cartago "prompted a cultural excavation of a site of remembrance, of history (Caesar, the Scipios, and the destruction of Carthage), and of legend (Dido and Aeneas)» (60). Pero los tapices, afirma poco después, se asemejan en su función a la urna de la Égloga II, con sus frisos conmemorando las hazañas del Duque de Alba: los frisos de la urna, esculpidos por el Tormes, fueron hechos públicos a través de un proceso de desciframiento, escritura y reproducción oral, tal y como los tapices fueron elaborados en privado desde la selección y ordenación de eventos antes de ser expuestos en público como homenaje a Carlos V, capturando fragmentos de una historia oficial autorizada. El imperio hispano se celebra desde lo que denomina una "contra-narrativa" (counter-narrative), que denuncia los desastres de la guerra, percibiéndose en el verso garcilasiano cierta resistencia a «the grand imperial narrative of conquest» (37). Como resultado, la «agonía erótica» que presenta Garcilaso a través de la auto-inmolación de Dido y su identificación personal con las mujeres tunecinas equilibran, en cierta forma, la visión triunfalista de Sepúlveda.

El tercer capítulo, «Objects of Dubious Persuasion», se centra en la Ode ad florem Gnidi, en la cual el poeta celebra una serie de elementos poéticos - una lira, carros triunfales romanos, una viola y una cítara, un cuadro, una estatua de mármol... - con el fin de "structure an irreverent act of persuasion and to figure the players, a spurned lover and an unresponsive beauty, at the centre of his tongue-in-cheek performance» (61). Como ya se ha dicho, Garcilaso rompe el delicado equilibrio emanado de la lírica petrarquista entre belleza y castidad con el fin de enfatizar la sensualidad de Violante y curar así el despecho de su amante. La aventura petrarquista, escribe Barnard, "has been reduced to simple erotic persuasion and conquest» (73). Quizá lo más original e interesante del capítulo sean las apreciaciones sobre el cuerpo abierto de Anaxarete, que aquí se relacionan con las ilustraciones de anatomía más importantes del periodo como fueron los Commentaria (1521) e Isagogae breves (1522) de Berengario da Carpi, 
o las de Andrea Vesalio en el De humani corporis fabrica (1543). La estancia de Garcilaso desde fines de 1529 hasta la primavera del año siguiente en Bolonia - a la sazón centro de anatomía en Europa- debió alimentar su interés y curiosidad en el funcionamiento de las vísceras y en el efecto visual del cuerpo abierto, dando lugar a lo que Barnard denomina una «discursive vivisection, like the actual dissection in anatomy theatres, trod on forbidden ground» (76). ${ }^{9}$

"The Mirror and the Urn» es el título del cuarto capítulo, en el cual se hace parada en la segunda Égloga y en dos objetos en particular: una urna y un espejo. En el poema, como sabemos ya, Albanio habita un mundo interior de introspección, mientras que Fernando, tercer Duque de Alba, vive en la esfera pública de las armas. Para la autora estos dos objetos son activos partícipes en un viaje de descubrimiento. Garcilaso nos hace ver que el texto como espejo se convierte en una poderosa herramienta que lleva a Barnard a preguntarse: "What did it mean to look at one's reflection in a mirror and to locate the self within? What type of knowledge was received and what type of image was constructed?» (82). Son estas dos preguntas que adquirirán especial relevancia un siglo después con la llegada a la Península Ibérica del telescopio galileano y su asimilación por una sociedad cortesana no del todo rendida a sus poderes visuales. En este caso, Garcilaso ofrece ya un precedente de gran atractivo al construir los paisajes del solitario pastor Albanio como nuevo Narciso, compartiendo las aguas reflectantes con Camila. Al introducir un personaje femenino, sugiere Barnard, el vate toledano amplía el papel del espejo como mediador de auto-revelación y auto-definición. El libro analiza lo que aquí denomina «the mapping of the self, male and female» (83) a la luz del tropo del autorretrato en la pintura del momento, y en particular en piezas como el Autorretrato en un espejo convexo de Girolamo Francesco Maria Mazzola, 'Parmigianino' (1524), que se presta a una estimulante comparación con la égloga en la medida en que ambas piezas exploran la eliminación de fronteras en el espejo como lugar de ilusión y artificio. ${ }^{10}$ La interpretación fallida de Albanio, la proyección de su psique fragmentada o las imágenes ilusorias de su caos interno apuntan a una suerte de «deception of self-imaging» (82). Al igual que Parmigianino, Garcilaso juega con el espejo para presentar su conducta dentro de los espacios limítrofes entre fantasía y realidad. El espejo, a fin de cuentas, no solo fue «a durable object useful for reflecting the material world», sino también «a multivalent tool equally capable of de-materializing the viewer and his optics, and of confounding as well as confirming the self's image of itself» (100).

Dos capítulos más completan el estudio: en el quinto, «Eros at Material Sites», se estudia la relación entre interioridad y materialidad en un yo poético

9. Esta representación artística fue ya magníficamente ha analizada por Sawday (1995).

10. Para una interpretación igualmente sugestiva de la confluencia entre poesía, pintura y óptica -en este caso a través del cuadro de Tintoretto Venus, Volcano y Marte- véase Noble-Wood 1-4. 
desestabilizado por el eros melancólico. Desde la relectura de cuatro poemas (sonetos XI y XIII, canción IV y soneto v), Barnard estudia las formas en que Garcilaso explora el universo del amante melancólico a través de actos de introspección y proyección de lugares concretos. Y el capítulo último, «Staging Objects in Pastoral», nos brinda una interpretación de la Égloga I siguiendo algunas tesis de Catherine Richardson y de su trabajo sobre la cultura material en Shakespeare, en donde se escogen objetos "con los que pensar» (good for thinking with) en su inmanencia y durabilidad. ${ }^{11}$ Estos objetos definen el carácter de Galatea y Elisa, así como las cualidades de las relaciones entre los pastores: «The discursive nature of the material» — concluyen estas páginas— «is underscored by the privileged figure of the text as mirror (the classical and Italian model that at each step subtends the poem) and by the pastoral waters as mirror, a site that is for Salicio an ambiguous tool that simultaneously affirms and deceives, and that for Nemoroso serves as a mirror of memory» (152). Cabe esperar que, en trabajos futuros, Barnard ofrezca nuevos objetos «con los que pensar» en autores coetáneos al aquí estudiado - incluyendo a italianos y neolatinos-, pues su exploración sugiere que las relaciones entabladas en estos años de fructíferos intercambios fueron numerosas.

Los estudios aquí comentados resultan de enorme utilidad para todos los interesados en adentrarse por primera vez en la obra garcilasiana, tanto como para aquellos que busquen darle un nuevo enfoque a piezas ya conocidas. De igual manera, son reflexiones que sirven de excelente herramienta educativa, tanto para estudiantes de licenciatura como de doctorado. Sus enfoques y propuestas nos recuerdan que la poesía garcilasiana transforma mito en materia y hace materia poética del mito dotándole de un nuevo aliento, porque es mito también quien la elabora y la da forma en su imperecedera temporalidad.

11. Richardson (2011).

*Agradezco a los evaluadores de este trabajo sus útiles comentarios de sugerencias. 


\section{Bibliografía}

Barnard, Mary E. Garcilaso de la Vega and the Material Culture of Renaissance Europe, Toronto, University of Toronto Press, 2014.

Barnard, Mary E. y Frederick A. DE Armas, eds., Objects of Culture in the Literature of Imperial Spain, Toronto, University of Toronto Press, 2013.

Brooks, Cleanth, The Well Wrought Urn. Studies in the Structure of Poetry, New York, Mariner Books, 1956.

Buchli, Victor, The Material Culture Reader, London, Bloomsbury, 2002.

García Santo-Tomás, Enrique, Modernidad bajo sospecha: Salas Barbadillo y la cultura material del siglo XVII, Madrid, Consejo Superior de Investigaciones Científicas, 2008.

-, La musa refractada: literatura y óptica en la España del Barroco, Madrid, Frankfurt, Iberoamericana / Vervuert, 2014 (reed. 2015).

Greene, Roland, Five Words: Critical Semantics in the Age of Shakespeare and Cervantes, Chicago, University of Chicago Press, 2013.

GutiÉrrez, Carlos, La espada, el rayo y la pluma: Quevedo y los campos literario y de poder, West Lafayette, IN, Purdue University Press, 2005.

Hernando Sánchez, Carlos José, El reino de Nápoles en el imperio de Carlos V: la consolidación de la conquista, Madrid: Sociedad Estatal para la Conmemoración de los Centenarios de Felipe II y Carlos V, 2001.

-, Castilla y Nápoles en el siglo XVI: el virrey Pedro de Toledo: linaje, estado y cultura (1532-1553), Valladolid: Junta de Castilla y León, 1994.

Mancall, Peter y Daniela Bleichmar, eds., Collecting Across Cultures: Material Exchanges in the Early Modern Atlantic World, Philadelphia, University of Pennsylvania Press, 2013.

Marcaida López, José Ramón, Arte y ciencia en el Barroco español. Historia natural, coleccionismo y cultura visual, Madrid, Marcial Pons / Fundación Focus Abengoa, 2014.

Miller, Daniel, Stuff, London, Polity, 2009.

Noble-Wood, Oliver J., A Tale Blazed Through Heaven. Imitation and Invention in the Golden Age of Spain, Oxford, Oxford University Press, 2014.

Richardson, Catherine, Shakespeare and Material Culture, Oxford, Oxford University Press, 2011.

SawdaY, Jonathan, The Body Emblazoned: Dissection and the Human Body in Renaissance Culture, London, Routledge, 1995.

TIlley, Christopher, et al., eds., Handbook of Material Culture, London, SAGE Publications, 2013. 